\title{
Putting Health Back in China's Development
}

Sarah Cook

\section{OpenEdition}

Journals

Édition électronique

URL : http://journals.openedition.org/chinaperspectives/2103

DOI : 10.4000/chinaperspectives. 2103

ISSN : 1996-4617

\section{Éditeur}

Centre d'étude français sur la Chine contemporaine

Édition imprimée

Date de publication : 15 septembre 2007

ISSN : 2070-3449

\section{Référence électronique}

Sarah Cook, " Putting Health Back in China's Development », China Perspectives [En ligne], 2007/3 |

2007, mis en ligne le 01 septembre 2010, consulté le 28 octobre 2019. URL : http://

journals.openedition.org/chinaperspectives/2103; DOI : 10.4000/chinaperspectives.2103

(C) All rights reserved 
[

\title{
Putting Health Back in
}

\section{China's Development}

\author{
SARAH COOK
}

A precondition for a harmonious society must surely be a healthy population; conversely a society that fails to deliver basic, affordable health care is likely to lack the social cohesion central to the concept of a harmonious society. This article examines the challenges China faces in improving health care provision, reducing health inequalities, and reviving a development strategy which prioritises good health as a basic right of all citizens.

A main social target of governments, international organisations and the whole world community in the coming decades should be the attainment by all peoples of the world by the year 2000 of a level of health that will permit them to lead a socially and economically productive life. Primary health care is the key to attaining this target as part of development in the spirit of social justice. (Alma Ata Declaration, WHO, 1978) ${ }^{(1)}$

$\tau$ $n$ the very year that China began to pursue its "open door" reform agenda, the international community called for "Health for All by the Year 2000"-a declaration heavily influenced by the very model that China was about to abandon. By 2000, not only had China's collective primary health care model essentially collapsed under the pressure to commercialise, but achievements of the pre-reform era were slipping. Rates of infant, child and maternal mortality had declined spectacularly up to $1980,{ }^{(2)}$ while life expectancy doubled; during the following two decades the improvements slowed or even showed reversals.

Such trends are indicative of a deep malaise in China's health system. Poor health and health care are a source of deep anxiety, at times erupting into protest; citizens are frustrated at rising costs and poor quality of services; officials and health providers are being tasked with delivering better services at affordable cost with limited resources. Reinforced by media coverage, ${ }^{(3)}$ public concern has escalated through a series of actual or incipient crises of public health: the emergence or resurgence of infectious diseases from SARS and Avian Flu to TB and hepatitis, the blood scandals associated with the spread of HIV-Aids, occupational health, workplace accidents, consumer and food product safety, and environmental pollution, have all become issues of public concern.
Crises of public health and associated international pressures, together with domestic recognition of the vicious and persistent cycle of poverty and ill-health, have combined to push the government of China towards public acknowledgement that the marketisation of welfare goods, including health, has gone too far. This was articulated most succinctly in a widely publicised report by researchers at the State Council's Development Research Center. ${ }^{(4)}$ In this context, a revival of a "people-centred" (yi ren wei ben) development ideology which aims to achieve a "well-off" (xiaokang) and harmonious (hexie) society, should return health to its place as an integral part of development. The re-articulation of a vision of human development is visible in official documents including the Eleventh Five-Year Plan and embedded in the goals of a harmonious society.

This article starts from the premise that a harmonious society-one that includes social equity and justice among its core principles-must surely be one with a healthy population, and a commitment to limit gross inequalities in health and health care. Inequalities-whether in health status, or in factors such as income and access to other resources which in turn determine health-are a key source of social tension. Conversely, a society that fails to provide even basic, affordable health care to its most vulnerable members is likely to

1. For the full declaration see www.who.int/hpr/NPH/docs/declaration almaata.pdf.

2. For example, under-five mortality declined from 225 per thousand live births in 1960 to 64 in 1980

3. Chinese and international media frequently report on health-related issues like lead poisoning in Gansu or a scandal over baby milk among others; on the costs of care see "China preventive medicine pits doctor against system," Wall Street Journal, 16 January 2007.

4. An English version prepared for the WHO Commission on Macroeconomics and Health by the WHO, Beijing and the State Council Development Research Center, China: Health, Poverty and Economic Development, December 2005 is available at http://www. who.int/macrohealth/action/CMH China.pdf. 
lack the social cohesion that must lie at the core of a harmonious society.

The article explores some of the challenges currently facing China as it struggles to reverse declining indicators of health and to reduce the deeply entrenched exclusions evident in its health sector. It asks what opportunity the policy focus on achieving a harmonious society offers for addressing or resolving current challenges in the health sector. Starting from the premise that the achievement of a harmonious society involves a significant role for government, this article considers the public finance and governance implications of this objective. The discussion focuses in particular on the New Co-operative Medical System (NCMS) as the main initiative to address the crisis of rural health care. The greatest barriers to health care are faced by the rural population, particularly in poor regions: improving the rural health system will thus be key to reducing current inequalities. The paper concludes with a discussion of the broader question: what would a development strategy look like if health was given a central place?

\section{Health and Development: Multiple Determinants, complex Interactions}

Unpacking a relationship between health, health care and "social harmony" requires thinking about the multiple channels that determine health outcomes. From the perspective of achieving the government's goal of a harmonious society, the focus is on distributional issues: inequalities associated both with access to resources and outcomes that may-if unchecked-lead to expressions of dissatisfaction and social unrest. Health is produced by a complex array of factorsfrom decisions and behaviour by individuals and within the household, to the wider environment in which people live, the quality of treatment they receive, and-in a commercialised system-the ability to pay for services when required. Those with the greatest health needs are generally those least able to access the necessary "inputs" (nutrition, sanitation, a pollution-free or safe environment, etc., as well as health care) required for good health. Barriers to health care are inevitably more acute for people in impoverished, rural areas, isolated from facilities and good doctors, and for groups that are vulnerable to ill-health-including the very young, elderly or disabled. The picture is further complicated by the speed and simultaneity of China's multiple transitions-including urbanisation, demographic aging and epidemiological changes-which generate their own distinctive health outcomes.
What challenges does this complexity create for achieving a harmonious society? To what extent are health inequalities or problems linked to other inequalities and potentially to sources of unrest? Apart from the obvious relationship between poverty and ill-health, there are clearly numerous pathways (in both directions) between health and aspects of "social harmony" or a cohesive and stable society. Consequently, many of the issues raised above cannot be addressed solely through the health system: the manifestations and their solutions relate to a broader development strategy. They involve addressing a range of policy areas-for example, aspects of the rural-urban divide, the working conditions and access to services of migrant workers; food and other product safety concerns; environmental health problems, and issues such as blood selling. While we return in our concluding remarks to some of these broader issues, and the question of what it would mean to place health at the centre of a development strategy, in the following sections we focus principally on what can be achieved through the health sector.

What contribution does the notion of harmonious society potentially make to addressing these complex problems? Its value lies in being a discourse that opens space for debate about health care and the responsibility of government for its provision and financing, and particularly for those seeking to counter the dominant view of health care as essentially a market commodity. Such a narrative is important in enabling officials at all levels to shift policy priorities, pursue innovation and take risks. ${ }^{(5)}$ It raises potentially sensitive issues around resource allocation, expenditure responsibilities between different sectors and levels of government, and mechanisms of accountability. This space can be used to question and monitor budget allocations, the extent to which fiscal transfers and government expenditures are pro-poor or equalising; whether sectoral expenditures operate as a mechanism of social protection, contributing to the reduction of poverty and inequality; or how different systems of payment or provision might serve as mechanisms for social cohesion. Many of these issues are critical to reforms in specific sectors, such as health; but cannot be resolved exclusively within any one sector. Moreover, failure to address these larger systemic and institutional issues will undermine efforts at sectoral reform. ${ }^{(6)}$

5. This point was illustrated by discussions among county, provincial and central health sector officials at project meetings and workshops, as different actors assessed the space for innovation or reform, and used official language of the leadership to justify their arguments.

6. These points have been argued particularly by scholars of China's fiscal system: for recent analyses, see V. Shue and C. Wong (eds), Paying for Progress in China: Public Finance, Human Welfare and Changing Patterns of Inequality, London, Routledge, 2007. 

labour force. Equitable and affordable health care for all (as recognised by the Chinese pre-reform system and the Alma Ata declaration) must be a key element of an integrated antipoverty strategy and the achievement of the broader social and economic goals associated with the harmonious society. Some key principles for attention if the reform of the health sector is to meet these broader social and economic goals would include the following:

- Access: how can health services reach the poor, those who are most marginalised and excluded (by virtue of location, income or identity)?

- Responsiveness: how can health services be made more responsive and accountable to the health needs of individuals and communities?

- Quality: how can the quality of service delivery be guaranteed and regulated?

- Fairness: What does "equity" in financing mean-should the state subsidise health care for all or just the poor?

\section{China's Rural Health Care: Inequalities and Disharmonies}

The pre-reform rural health care system, widely admired by health experts the world over, remains a model of what a low income economy can achieve through specific institutional arrangements. ${ }^{(8)}$ Impressive improvements in health status were attained through the Co-operative Medical System, which delivered public and primary health care through mass health campaigns, village health workers or "barefoot doctors", and a three tier system of village clinics, township health centres and county level hospitals for the treatment of more serious illnesses. While there are no doubt lessons from this experience, it is clear that the model is no longer appropriate to China's current institutional and economic arrangements. ${ }^{(9)}$

Decollectivisation resulted in most village clinics being contracted out to "barefoot doctors" with service provision effectively privatised; access to curative services was mainly on a fee for service basis, while public health functions and preventive services were neglected. The share of villages with Co-operative Medical System declined from an estimated $90 \%$ in the late 1970 s to under $5 \%$ by 1984 . ${ }^{(10)}$ Many doctors stopped practising medicine to take up more lucrative income-generating activities; for those that remained, incomes largely depended on profits from the sale of drugs.

The next two tiers were similarly affected. Township health centres remain responsible for delivering basic out-patient services, birth delivery and related (pre- and post-natal) care, some testing or diagnosis, and referral where appropriate to the county level hospital.

Some township health centres have more extensive in-patient facilities but most are poorly equipped and staffed. County level hospitals are generally better equipped and staffed to provide a wider range of in-patient services; there is a greater choice at this level with government general hospitals, more specialised facilities, as well as the emerging private sector. Public facilities at both levels suffer from similar problems: they are often over- or inappropriately staffed with limited control over personnel decisions. Particularly at the township level, facilities are under-utilised. Given the expenditure responsibilities of local governments, health facilities have-like other branches of government-responded to incentives to raise revenues through fees from (often unnecessary) testing and profits from drugs, revenues which are used to supplement or even to pay the basic salaries of staff. Inevitably this process has led to the deterioration of quality, and the provision of inappropriate and costly services. Public health has been a major casualty of this excessive dependence on market forces within the health sector and the collapse of the three tier rural system.

By 2002 the share of government and insurance payments had fallen to only $33 \%$ of all medical costs, with individuals paying $67 \%$ as out of pocket expenditures (up from $20 \%$ in 1978). An average in-patient spell involved out of pocket expenditures equivalent to $60 \%$ of annual per capita consumption. (II) According to WHO's World Health Report 2003 out of pocket expenditures as a share of private expenditures were $87.6 \%$, with only $5.8 \%$ of private expenditures being pre-paid. A system so dependent on an individual's ability to pay for services inevitably results in serious disparities in health access and outcomes, exacerbating underlying and persistent social and economic inequalities. ${ }^{(12)}$

8. There is an extensive literature on the pre-reform health system and the impact of decollectivisation; for a recent summary see J. Duckett "Local governance, health financing, and changing patterns of inequality in access to health care" in Shue and Wong, Paying for Progress, op. cit.

9. For an extended discussion of this argument, see Gerald Bloom and Fang Jing, "China's rural health system in a changing institutional context," IDS Working Paper 194, July 2003.

10. Duckett, op. cit., p. 52.

11. While there is no clear definition of what share constitutes "catastrophic" spending, shares used range from about $5 \%$ to a high of $40 \%$. These levels are thus very high by international standards; see for example X. Ke et al., "Household catastrophic health expenditure: A multicountry analysis", The Lancet, Vol. 362, 12 July 2003, pp.111-17.

12. This inequality was reflected in China's low ranking on health distribution by the World Health Organisation. See WHO World Health Report 2000, p.185. 
$\pi$

\section{$>$ Challenges to health equity}

Under these circumstances, challenges to the achievement of greater equity in health status and provision lie both in persistent inequalities inherited from the pre-reform era, in some cases exacerbated by rapid growth, as well as new risks and vulnerabilities associated with the transition to a market economy. Regional, institutional or policy induced inequalities-such as rural-urban dualism-interact with disparities based on individual identity, including age, gender and ethnicity, generating entrenched social and cultural exclusion. Extending quality health care to excluded groups, often located in remote, mountainous rural areas, traditionally marginalised from systems of state delivery and with limited capacity to utilise market-based mechanisms, poses challenges of provision, access and finance. These challenges are outlined below, drawing on a range of data sources as well as interviews and field visits conducted from 2006-2007 with the aim of assessing the social dimensions of health system reform.

China's remarkable success in reducing poverty is well-documented. Based on the official poverty line, the number of rural people living in absolute poverty fell from 85 million (9.6\% of the rural population) in 1990 to 26.1 million $(2.8 \%)$ by the end of 2004 . However, the removal of traditional safety nets and the rise in user fees for health and other public goods has hit the poorest and most vulnerable households hardest. For rural households, income or economic status remains the major determinant of access to health care. Analyses of the National Health Survey data reveals stark differences between the top and lower two quintiles on indicators relating to ability to pay (such as self-discharge from hospital and non-use of in-patient services when referred), with financial difficulty cited as the reason. ${ }^{(13)}$ Similarly, the 2003 National Health Services Survey of 11 western provinces found that $27 \%$ of poor households were impoverished due to illness or injury.

Within the household, gender and age create further differentials in needs and access. Gender remains a deeply entrenched dimension of inequality and-given women's reproductive roles-one with particular significance for health. Evidence points to gender disparities in access and utilisation of services, but analysis is hampered by a lack of systematic sex-disaggregated data. The 2002 Second Chinese National Sample Survey on Women's Status found that $60.9 \%$ of rural women compared with $21.8 \%$ of rural men delayed seeking medical treatment when needed; the 2000 Census found infant mortality rates for girls to be approximately $40 \%$ higher than for boys, while Under Five Mortality in 2004 was 27 for boys compared with 36 for girls. Evidence on reproductive health suggests serious problems of recognition and access to treatment; ${ }^{(14)}$ interviews highlighted the unwillingness to talk to male doctors about many conditions, a problem that may be exacerbated by ethnicity. ${ }^{(15)}$ These barriers are not necessarily technically difficult to overcome: the problem lies in awareness and willingness to allocate resources.

Access may be affected both positively and negatively by migration, both for migrants and those left behind. On the one hand, financial pressures can be relieved by remittances; on the other, rural residents-often the elderly and infirm, along with women and children-may find physical obstacles such as distance and transportation harder to overcome. For migrants themselves, questions of access in their places of work are related to the cost of services. For policy makers, the issues relate to public health issues associated with migrants: in urban areas, they are often stigmatised as likely carriers of infectious diseases and violators of family planning policies. At the same time, few cities take responsibility for the services and infrastructure needed to ensure their health. Migrants are particularly vulnerable to occupational ill-health arising from their work environments or work accidents. The ill-health of migrants, often as a result of workplace health hazards, can be devastating for rural households affecting as it does working age, income-generating household members. From the policy-makers' perspective, recent debates have emerged over whether migrants should be covered through the rural or urban "insurance" schemes. While some urban schemes have now been expanded to include non-residents (though generally too costly for migrants), the NCMS encourages participation of all household members (including migrants), but rarely reimburses costs of services elsewhere, or makes it inconvenient to do so. For NCMS managers, there is a clear incentive to increase membership and therefore contributions, especially where utilisation of services may be limited (by distance). For migrants, especially for predictable health care needs such as giving birth, it is often cheaper to return to rural areas than to give birth or receive treatment in cities. However, as an increasingly fragmented

13. S.Tang and J.Gao, "Equity in Health Care among Different Income Groups", Presentation on Findings of 3rd National Health Survey, Beijing, December 2004.

14. See for example Green Book of Women: 1995-2005, published by the All China Women's Federation Women's Studies Institute, 2006. See also the Report on gender equality and women's development in China.

15. For example among Hui women in Ningxia. 


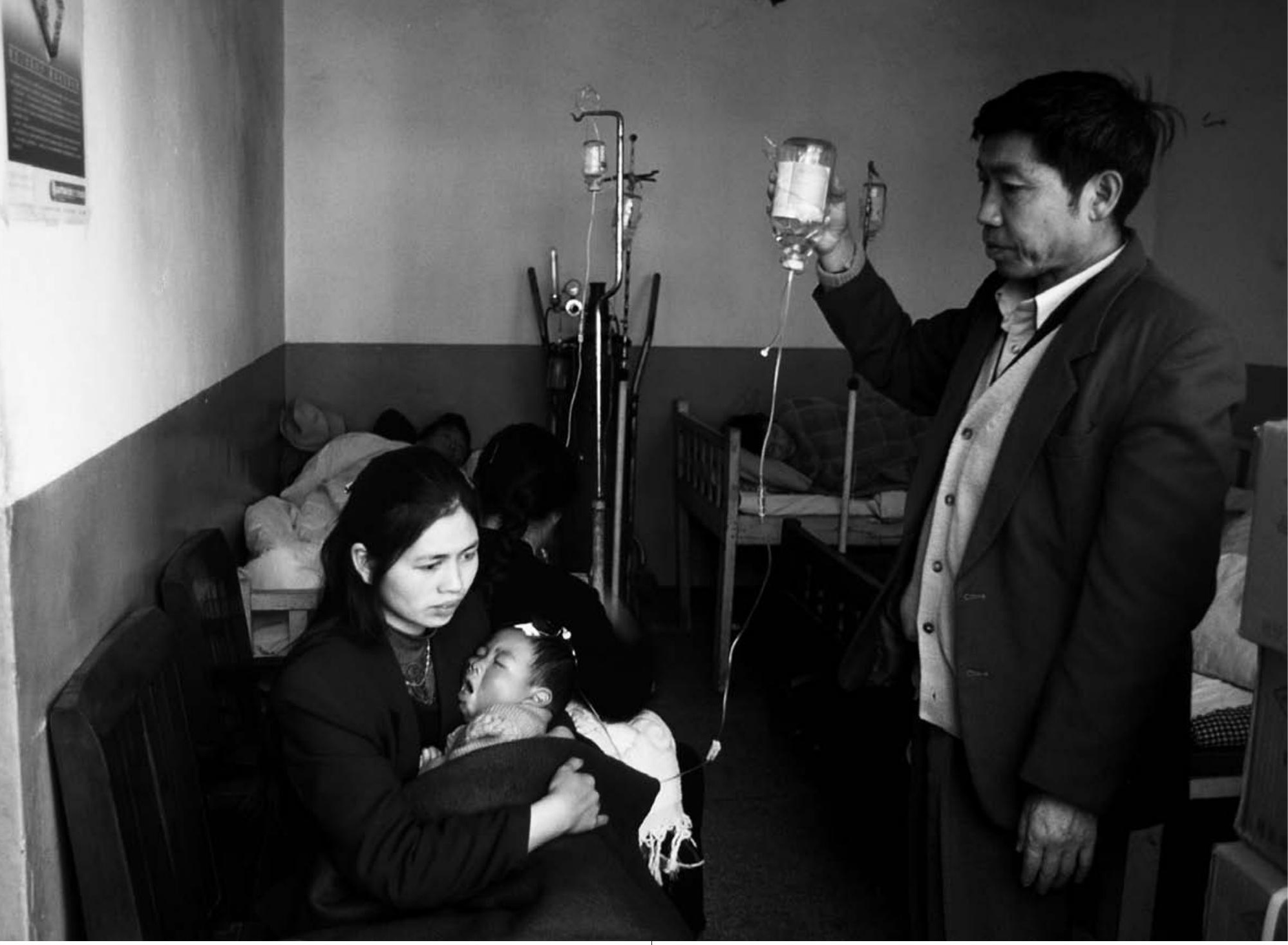

\section{Hospital in the countryside}

system of separate insurance schemes develops, the difficulties of integrating these to ensure the needs of different groups are met will also increase.

Spatial inequalities create further challenges to provision. The most deep-rooted disparities arise from the stark urbanrural structural inequalities institutionalised at the individual level through the household registration system, and are reflected in the skewed distribution of resources. According to $\mathrm{MOH}$ data, in 2004 approximately $65 \%$ of national health expenditures went to urban areas; $80 \%$ of medical facilities are in urban areas with $40 \%$ of the population; the rural population $(60 \%)$ are served by $20 \%$ of the facilities.

The rural-urban ratio in per capita health expenditures was 4.2:1 in 2004 (an increase from 3.8 in 2000), compared with a differential in household incomes of 3.2. Increases in individual health expenditures in 2003 were slightly higher in rural $(11.5 \%)$ than urban $(10.7 \%)$ areas despite a much lower increase in per capita income (5.9\% vs. $10 \%)$; $90 \%$ of rural health costs came from out of pocket expenditures compared with the average of around $60 \%$. ${ }^{(16)}$ The impact of these disparities in expenditures is reflected in unequal health outcomes: under five mortality in 2002 was 15 per 1000 live births in urban areas compared with 40 in rural areas. ${ }^{(17)}$

Spatial and regional inequalities are deeply embedded in China's fiscal system. Tax reforms failed to provide clear expenditure assignments among different levels of government, with the main responsibilities for public services such as basic education and health care remaining concentrated at the county level and below. ${ }^{(18)}$ Despite some clarification of

16. A Health Situation Assessment of the PRC, United Nations Health Partners Group in China p. 40; China Health Development Statistical Gazette 2005, published by the MOH and cited in UNICEF China Country office / NWCCW Financing Services for Children in China, Vol 1 (A review of expenditure in the education and health sector Wang X. August 2006); Hussain A. and N. Stern, Background paper for World Bank Conference on Public Finance for a Harmonious Society, Beijing, June 28-9, 2006, p. 15.

17. A Health Situation Assessment, op.cit., p. 30.

18. See for example Wong C. in "Paying for Progress", op. cit.; and background papers for World Bank Conference "Public Finance for a Harmonious Society", Beijing, June 28-9, 2006, especially J. Martinez-Vazquez, "Expenditure assignments in China" and Hussain and Stern, op.cit. 


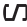

responsibilities, financing remains highly unequal: in 2004, the relative share for health care in total government expenditure at each level was $3 \%$ for the centre, $22 \%$ for provinces, $32 \%$ for prefectures and $43 \%$ at the county and below. ${ }^{(19)}$ In 2003, public expenditure per capita for the highest spending province was 8.5 times those of the worstoff; for health, the difference was over 13 times. The average expenditure per capita ranged from 341 yuan in Beijing to 25.3 in Hunan (the average being 74.0). Twelve provinces including most of the poorest western and central provinces recorded per capita expenditures under 50 yuan.

\section{Reducing disharmonies: Can the New Cooperative Medical System help?}

\section{Extending access through NCMS}

Given the disparities briefly reviewed above, what can be done to reduce health inequalities necessary for a harmonious society? The main initiative for expanding rural health care coverage is the "New Cooperative Medical System" (NCMS). Introduced in 2003, and inspired by its pre-reform counterpart, it is usually described as a form of insurance. Funded through a mixture of contributions from households (10 yuan per member), local and central government (20 yuan each per person) it aims to protect farmers in particular from catastrophic health expenditures. The NCMS is in theory voluntary, though with high levels of participation (around 75\%) and a goal of $90 \%$ coverage. Pooling takes place at the county level, making the risk pool relatively small, and the total amount of 50 yuan per person (raised in 2006 from the initial level of 30 yuan) falls far short of what would be needed to significantly reduce out of pocket expenses. It provides cover for certain predetermined health conditions; deductibles and co-payment rates are high and reimbursement mechanisms often complex. There is little evidence as yet that out of pocket payments, catastrophic spending or rates of non-health seeking behaviour have declined.

As a pilot policy, each county tends to develop its own approach though dominant models are emerging, varying in mechanisms and scope of coverage of in- and out-patient services. Evidence from an $\mathrm{MOH}$ study of NCMS pilot counties indicates the varied impact of different arrangements or reimbursement mechanisms, especially on the poor. In areas where the dominant approach was reimbursement for catastrophic illness the participation of the poor population was significantly lower (19\% of pinkun households and $45 \%$ of tekun) compared with $70-90 \%$ participation rates among these groups where the dominant scheme involved outpatient services or household accounts. By contrast for migrants, the participation rate was about $70 \%$ with catastrophic illness and family account schemes, but only $45 \%$ for outpatient service schemes. While not yet well understood, the design of schemes clearly has implications for the participation and ability to benefit of different population groups.

For rural residents classified as tekun or eligible for government relief, a Medical Assistance (MA) scheme is being developed. Centrally funded and operated through the Ministry of Civil Affairs, pilot MA schemes have generally paid NCMS contributions, and higher levels of co-payment to traditional beneficiaries of relief such as "Five Guarantee" (wubao) households. Coverage remains extremely limited, but the scheme is now being rolled out more widely. One estimates suggests that in areas with the scheme, about $5 \%$ of households receive assistance while approximately 20\% fall below the poverty line.

Perhaps a bigger challenge is how to meet the needs of the bottom third to half of the income distribution who are not poor enough to receive additional assistance through MA but often too poor to make the necessary co-payments required for treatment. Unlike MA recipients, these are working age people on whose income and health the livelihoods of other family members also depend. NCMS deductibles and co-payments amounting to around $60 \%$ of costs continue to make health care unaffordable, and this group remains at high risk of destitution due to catastrophic expenditures or chronic ill-health in the family.

As noted above, an additional challenge is meeting the needs of the vast migrant population. Concerns about health care coverage for this group appear to have risen on the policy agenda-largely in terms of their integration into NCMS From an urban perspective the concern is more often about migrants as a source of health "problems" (such as infectious diseases), and the need to provide family planning services to ensure population controls are maintained, rather than about the health and well-being of migrants themselves. The implications of China's deep rooted rural-urban dualism, however, means that integrating the rural and urban systems remains beyond the scope of most current policy discussions; migrants remain caught between the different schemes, none

19. Hussain and Stern, op.cit., p. 12. 
of which are designed to address their particular circumstances and constraints.

Given the recent introduction of NCMS, however, there is limited analysis of NCMS and MA participation, utilisation or reimbursement broken down by the key "social" dimensions discussed earlier. The main source of systematic information comes from the study of 27 pilot NCMS counties. ${ }^{(20)}$ In these, approximately 8.5 million people participated in NCMS of which $11 \%$ were classified as poor (pinkun), $4.16 \%$ a extreme poor (tekun), and 10\% were long-term migrants. In the counties located in western China, these shares doubled: of NCMS participants $21.5 \%$ were pinkun and $8.1 \%$ tekun. These counties also had a larger share of migrants. Regional inequalities also play out in the implementation of NCMS and MA. The 2003 National Health Survey illustrates the stark differences between east, central and western regions, as well as between and within provinces, in expenditures and participation. ${ }^{(21)}$ Of 27 pilot counties, those in the east and central provinces were more likely to have preferential policies, subsidies or fee reductions for the poorest. In wealthier regions the share of counties with such policies was $60 \%$ and $76-78 \%$ for pinkun and tekun households respectively, while in western provinces the equivalent shares were only $18 \%$ and $48 \%$. Poor regions are fiscally constrained from providing such assistance. Despite an increase in central government transfers to western provinces, the amounts involved fall short of what is needed to reduce overall disparities in spending or the burden on the poorest. While the program is relatively new and many questions remain, there are nonetheless clear indicators that the NCMS at current levels of funding can play only a limited role as an insurance scheme or in protecting households against catastrophic expenditures.

\section{Service provision and provider payment}

Can NCMS contribute to supply side reforms, leading to improved quality and lower cost of provision? Supply side or provider reforms are complex and often politically sensitive. They include the creation of appropriate incentives to, and the regulation and accreditation of, providers; payment mechanisms, drug pricing and procurement policies, and treatment protocols; developing the capacity of various levels of government to regulate and monitor together with transparent accountability mechanisms. Currently, patients and insurers rely mainly on fee-for-service payment, with prices regulated but distorted in ways which encourage over-supply of high-tech interventions and drugs. Drug pricing policy re- forms are being implemented in many areas, linked to NCMS. ${ }^{(22)}$ Reduced profits from drugs however mean that other revenues are needed to supplement salaries and operating costs. Resolving the payment of providers would be a major step towards changing the current incentive system. This would also require better accreditation and evaluation procedures for staff, together with more competitive and transparent staff and management selection procedures. Other reforms (also linked to NCMS) aim at rationalising service delivery through vertical integration with a referral system between village, township and county facilities. All of these reforms require more accountable and transparent governance, including for the management of NCMS funds, in order to rebuild trust in the health system.

\section{Conclusion}

The above discussion has briefly outlined key challenges to resolving the issues of inequality in China's health system. The government clearly needs to reverse excessive commercialisation, regulate providers and ensure that costs are controlled and quality improved. It is also clear that addressing the needs of the most marginalised cannot depend on market forces. While "market-like" mechanisms can create a degree of competition to control costs and improve efficiency, in the current situation of highly imperfect markets, perverse incentives and conflicting interests, the role of the state needs to be strengthened. This is particularly true if health is to be linked to the broader development objectives associated with harmonious society. From this perspective, the health system is part of a broader system of social protection-that is, a social mechanism to protect households and their livelihoods from risks such as ill-health. Access to treatment when required cannot depend on the ability of individuals to pay at point of delivery.

What would the health system look like if-following the logic of harmonious society-health was central to the idea of development? It would be part of a development strategy in which the state played a leading role in ensuring that the

20. Center for Health Statistics and Information, Ministry of Health, China's New Rural Cooperative Medicine: Progress and Effectiveness, 2005 Research Report on Pilot New Cooperative Medicine Scheme, Beijing, Zhongguo xiehe yike daxue chubanshe, 2007.

21. Center for Health Statistics and Information, Ministry of Health, An Analysis Report of National Health Services Survey in 2003, Beijing, Zhongguo xiehe yike daxue chubanshe, 2004.

22. In Ningxia a region-wide policy is in place unifying drug procurement and reducing profit margins effectively to zero (Field visit, December 2006). Elsewhere, counties have drug lists with set prices against which NCMS reimbursements can be made. 


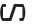

$\geq$ gains from growth were widely shared, that inequalities were managed and the fault lines among different population groups reduced. One of the key mechanisms for reducing disparities and ensuring appropriate institutional arrangements that do not exacerbate inequalities is the fiscal system-with transfers and resource allocation also directed to social investments such as health and education.

In terms of what this means for the health sector, evidence from across Asia and beyond points strongly to the advantages of tax financed systems if the goal is to achieve progressive outcomes and weaken the vicious cycle of poverty and ill-health. Across Asia, as elsewhere, tax-based systems (such as in Hong Kong) provide the most equitable and progressive outcomes; social health insurance (as in South Korea and Japan) is less so, though this depends largely on the nature of the social insurance system which can potentially build in a stronger element of redistribution. ${ }^{(23)}$ Universally-as would be expected-a system in which the user pays out of pocket is the least equitable and most highly regressive. Unsurprisingly this is common in poor countries and, as we have seen, in China.
There is a confusing array of arguments about the links between poverty, inequality, redistribution and growth. While the dominant neo-liberal discourse of the past two decades has prioritised market forces and a reduced role of the state, the idea that growth should benefit the poor-at least as much, and possibly disproportionately more-in order to limit inequality, has gained growing acceptance. Reliance on the market as the mechanism for ensuring growth reaches the poor presupposes a number of conditions: that the poor have opportunities, and the skills and health to take advantage of them. As noted earlier, health is not a market commodity; nor can it be viewed only in instrumental terms as a productive input. A view of health as a "right" comes closest to articulating the centrality of health to life, well-being and economic development. From this perspective, achieving a harmonious society will require a stronger commitment from the state to meeting the health needs particularly of China's rural population in order to reduce the inequalities that threaten social harmony. 